\title{
Identifying Soft Red Winter Wheat Cultivars Tolerant to Barley yellow dwarf virus
}

Randall Weisz, Associate Professor, Barry Tarleton, Research Technician II, and J. Paul Murphy, Professor, Department of Crop Science, North Carolina State University, Box 7620, Raleigh 27695-7620; and Frederic L. Kolb, Professor, Department of Crop Sciences, University of Illinois, 1102 S. Goodwin Ave., Urbana 61801

\begin{abstract}
Weisz, R., Tarleton, B., Murphy, J. P., and Kolb, F. L. 2005. Identifying soft red winter wheat cultivars tolerant to Barley yellow dwarf virus. Plant Dis. 89:170-176.

Barley yellow dwarf virus (BYDV) is a serious disease of soft red winter wheat. Although there has been interest in tolerant cultivars, identification and development has been slow due to a lack of precision in rating plants for response to BYDV. Visual ratings of symptoms are commonly used to evaluate cultivars, but these ratings have proven to be inconsistent. The objectives of this research were to assess BYDV visual symptom ratings of wheat cultivars under field conditions, to measure disease-related yield reductions in these cultivars, to determine if a relationship exists between BYDV visual symptoms and yield reductions, and to determine BYDV cultivar tolerance. A split-plot design with insecticide treatment (main plot) and 11 cultivars (subplots) was employed over 4 years. The overall relationship between symptom ratings and BYDV yield reductions was weak $\left(R^{2}=0.40\right)$ and not consistent across years or cultivars. A consistency of performance analysis showed cultivars clustered into five distinct tolerance classes. Under conditions of high BYDV infestation, visual symptom ratings could be cautiously used to identify highly tolerant cultivars. The most reliable method for rating cultivar tolerance was a direct measure of disease-induced yield reduction across multiple environments.
\end{abstract}

Additional keywords: relative yield, visual disease symptom rating

Barley yellow dwarf virus (BYDV) is the most serious virus disease of southeastern U.S. soft red winter wheat (Triticum aestivum L.). The disease results in stunted growth, reduced kernel size, and fewer kernels per head $(9,10,17)$. Reductions in winter wheat yield from 34 to $91 \%$ due to BYDV have been reported $(3,6,9,16,17)$.

Transmission of the virus to wheat in the southeastern United States is by the bird cherry-oat aphid (Rhopalosiphum padi (L.)) and the English grain aphid (Sitobion avenae (Fabricius)) in the fall and spring, respectively (4). Because fall infections are generally more serious than spring infections $(8,9)$, attempts to reduce damage caused by BYDV have included fallapplied foliar insecticides or application of insecticidal seed treatments. Foliar insecticides have not proven to be reliable because fall aphid infestations can occur anytime during periods of warm weather, and disease transmission can occur even when aphid population densities are low. Imidacloprid applied as a seed treatment

Corresponding author: R. Weisz

E-mail: Randy_Weisz@ncsu.edu

Accepted for publication 22 September 2004.

DOI: 10.1094/PD-89-0170

(C) 2005 The American Phytopathological Society
(GAUCHO; Gustafson, Inc., Dallas, TX) has proven to be highly effective against aphid infestation and subsequent transmission of BYDV $(7,21,22)$. Southeastern wheat producers, however, have not widely adopted imidacloprid seed treatment due to its relatively high cost and because a grower-applied formulation is not currently available. Chapin et al. (4) reported that delayed planting was an effective means of preventing early BYDV infections, but the associated yield reduction makes this an impractical production practice.

Improved host plant tolerance would be a cost efficient approach to BYDV management, but identification and development of tolerant cultivars is difficult due to lack of precision in rating plants for response to infections (14). Visual rating systems of plant symptoms have inconsistent correlations with other measures of disease severity. Carrigan et al. (3) found that the degree of leaf chlorosis was not a reliable measure of variety tolerance, but Lorens et al. (14) found that BYDV RNA concentration in six cultivars was closely correlated with visual symptom ratings. Hoffman and Kolb (10) rated disease incidence in soft red winter wheat based on the percentage of plants in field plots showing visual symptoms. They reported that even when $90 \%$ of the plants tested positive for presence of the virus, visual ratings could still be as low as $17 \%$. Furthermore, in 2 years of field experiments, visual symptoms were negatively and positively correlated with yield in years one and two, respectively. In other words, it was possible to have circumstances where higher yield was associated with greater symptom expression. Hoffman and Kolb (10) suggested that variety tolerance might best be measured using BYDV-related yield reductions instead of visual ratings. In spite of these reports, visual rating systems are probably the most common tools small grain breeders use to evaluate soft red winter wheat lines for BYDV tolerance.

A second complexity to developing cultivars with BYDV tolerance is the difficulty associated with establishing uniform infections across large numbers of plots. When field experiments are dependent on naturally occurring aphid populations, infections do not always develop. Additionally, even in years when aphid populations are high, the resultant naturally occurring BYDV infections may not be spatially uniform across all experimental plots. To overcome this, some researchers inoculate small field plots or hills with laboratory reared aphids known to be carrying BYDV (10). Although assuring infection, this approach is costly and demands the maintenance of aphid colonies.

This research was undertaken in light of the need for tolerant wheat cultivars and the uncertainty associated with using visual rating systems (especially under naturally occurring infections) for their evaluation. Our specific objectives were (i) to assess BYDV visual symptom ratings of commercial soft red winter wheat cultivars under natural BYDV infections, (ii) to measure the disease-related yield reductions in these cultivars, (iii) to determine what, if any, relationship may exist between BYDV symptom expression and yield reductions, and (iv) to determine the level of BYDV tolerance of each cultivar.

\section{MATERIALS AND METHODS}

Studies were conducted over four seasons from 1999 to 2002 at the Piedmont Research Station in Salisbury, NC. This location was chosen because BYDV infections occur there in most years. In 1999, eight soft red winter wheat cultivars (Agripro Patton, Agripro Shelby, FFR 555, Jackson, C 9543, C 9663, P 2580, and P 2684) were evaluated in a split-plot design with four replications. In 2000, 2001, and 
2002, three additional cultivars (Agripro Hickory, Roane, and USG 3209) were added to the experiment, which was enlarged to include five replications. Main plots were GAUCHO treated and untreated, and subplots consisted of the 8 or 11 cultivars. Seeds were no-till drilled into seven-row plots $8 \mathrm{~m}$ long in October of each year. Standard production recommendations for winter wheat in North Carolina (20) were followed to maintain adequate fertility and to assure that the plots were free from weeds, cereal leaf beetle (Oulema melanopa), and foliar fungal diseases.

All plots were evaluated for visual symptom expression during early to medium milk (growth stage 75) (23) using a 0 to 9 point scale based on a combination of BYDV incidence (percentage of a plot showing symptoms) and severity (degree of foliar discoloration and plant stunting). At maturity, plots were harvested with a plot combine equipped with an electronic weigh system.

Initial statistical analysis was conducted using classical ANOVA for a split-plot design by year using SAS PROC MIXED (18). In determining treatment or cultivar effects with the classical ANOVA, it is assumed that the model-fit errors are independent and identically distributed with the same variance. However, in these experiments, BYDV severity was expected not only to be due to treatment and cultivar effects, but also to be the result of natural aphid infestations and population development. Since it was unlikely that spatial patterns of aphid colonization would conform to the experimental blocking used in the field, it was anticipated that the resultant model-fit errors would be spatially correlated, violating the assumption of independence. To test this hypothesis, the spatial location of each plot was used to develop semivariograms (11) of ANOVA model-fit errors.

When spatially correlated errors are present, the efficiency of the classical ANOVA in estimating treatment comparisons and treatment means has been questioned (19), since the classical use of ordinary least squares (OLS) ignores local patterns of variability. Additionally, when errors are spatially correlated, OLS underestimates the variance of the error terms (15), and consequently, the resultant $t$ and $F$ tests may not be reliable. To overcome this problem, in addition to using classical ANOVA, randomized complete block with correlated errors analysis (RCBCE) and correlated error analysis without blocking (CE) were implemented in PROC MIXED (18). These analyses were undertaken by site-year for visual disease symptom ratings of the untreated plots, yield of the GAUCHO-treated plots, yield of the untreated plots, and relative plot yield (a measure of BYDV-related yield reduction calculated as yield of an untreated plot divided by the least square mean of the treated plots of the same cultivar at that site-year). For each variable of interest, the classical ANOVA was run first, then six RCBCE models (using spherical, exponential, and Gaussian spatial functions with and without nugget effects) were run, and finally six CE models (also using spherical, exponential, and Gaussian spatial functions with and without nugget effects) were run. The Akaike Information Criterion (AIC) (1) for each of the 13 models were compared, and the model with the lowest AIC was selected as having the best fit to the data (13). This "best fit" model was then used for estimating treatment effects, cultivar means, and separation of means.

In addition to a separation of cultivar means by year, cultivar relative yield was also evaluated using a "consistency of performance" analysis (12). In this analysis, cultivars are classified based on a plot of each cultivar's mean rank over years against the standard deviation of those ranks. By doing this, cultivars were classified as having consistent or inconsistent good, fair, or poor BYDV tolerance.

To better understand the relationship between relative yield and visual symptoms and how this relationship differed across cultivars, a linear-plateau function was used. Relative yield and visual symptom data across years for every cultivar was fit with this function using PROC NLIN (18).

\section{RESULTS}

Spatially correlated errors. Spatial correlation was found in many of the ANOVA model-fit-error data sets. For example, Figure 1 shows a semivariogram of model-fit errors for the 2000 untreated yield plots. Thirty-three percent of the residual variance was accounted for by spatial correlation, which existed over a range of $19.1 \mathrm{~m}$. Clearly, blocking did not

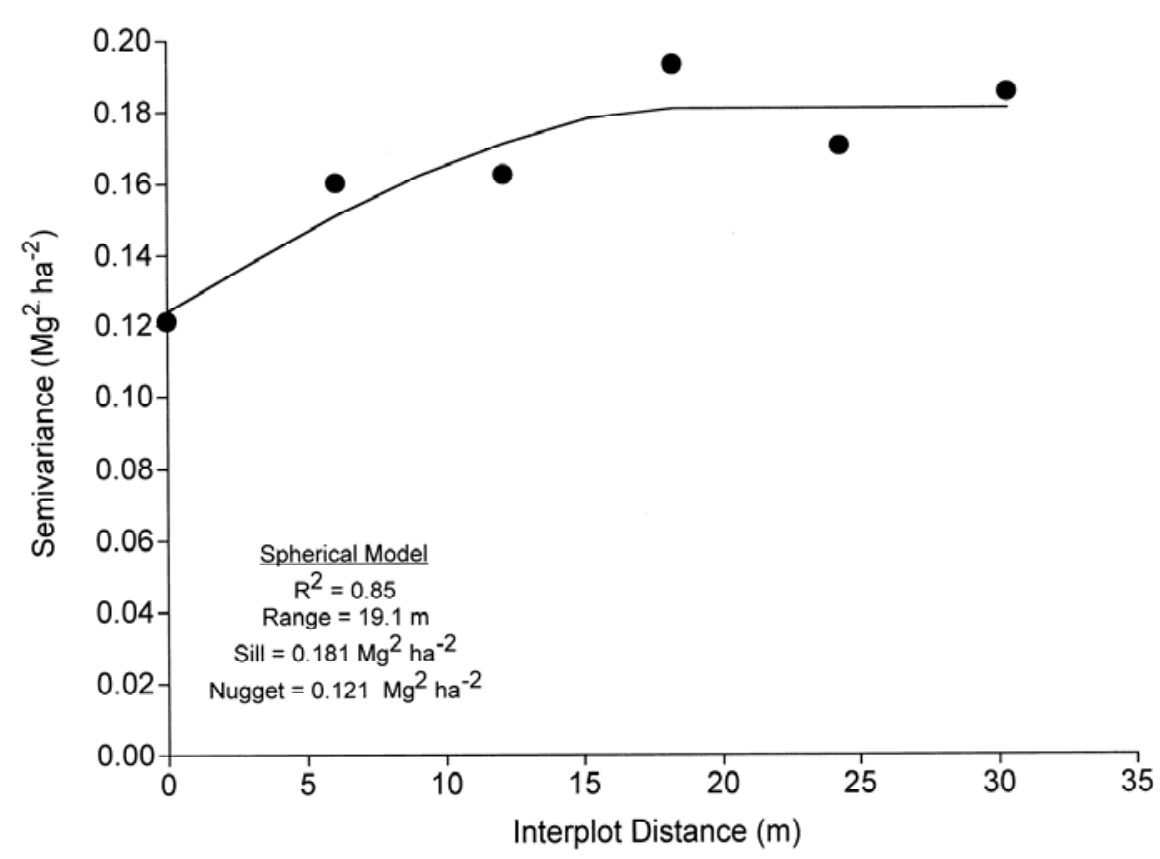

Fig. 1. A semivariogram of analysis of variance (ANOVA) model residuals for 2000 untreated yield. Data were fit using a spherical model, and the model parameters (nugget, sill, and range) are indicated.

Table 1. Best-fit models ${ }^{\mathrm{x}}$ used for data analysis of yield from untreated plots, yield from insecticidetreated plots, Barley yellow dwarf virus visual symptom expression, and relative yieldy

\begin{tabular}{lcccc}
\hline & \multicolumn{4}{c}{ Year } \\
\cline { 2 - 5 } & $\mathbf{1 9 9 9}$ & $\mathbf{2 0 0 0}$ & $\mathbf{2 0 0 1}$ & $\mathbf{2 0 0 2}$ \\
\hline $\begin{array}{l}\text { Untreated } \\
\text { yield }\end{array}$ & ANOVA & CE no-nugget & CE nugget & CE nugget \\
Treated & & Exponential & Gaussian & Caussian \\
yield & ANOVA & ANOVA & CE nugget & CE nugget \\
Symptom & & Gaussian & Spherical \\
expression & ANOVA & ANOVA & CE nugget & ANOVA \\
Relative & & Exponential & \\
yield & ANOVA & CE no-nugget & CE nugget & CE nugget \\
\hline
\end{tabular}

${ }^{x}$ Models tested included classical analysis of variance (ANOVA), randomized complete block with correlated errors analysis (RCBCE), and correlated errors analysis without blocking (CE).

${ }^{\mathrm{y}}$ Relative yield is defined as untreated yield divided by treated yield.

${ }^{z}$ When a CE or RCBCE model fits the data best, the associated spatial function used to describe the spatially correlated residuals is indicated. 

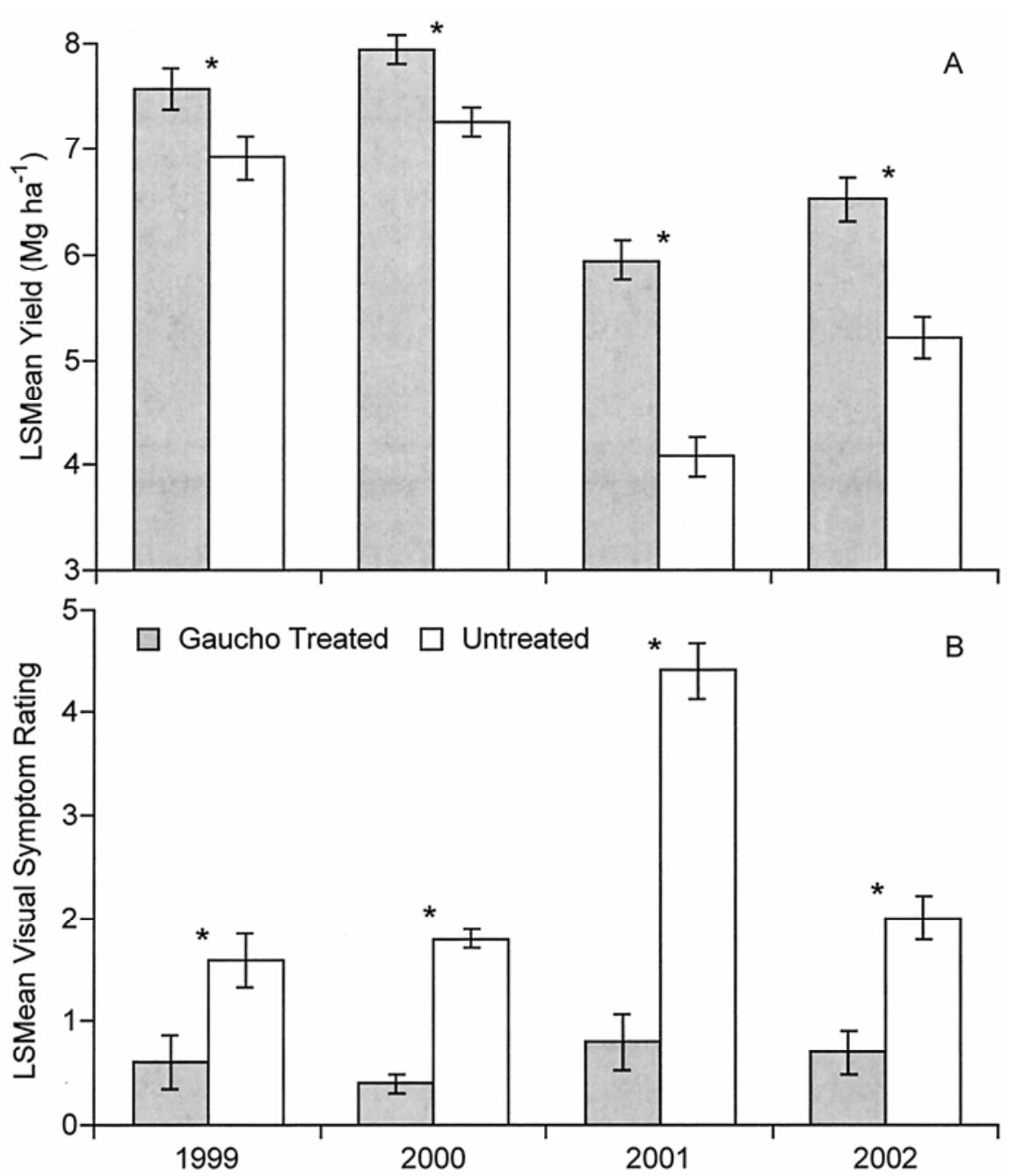

Fig. 2. Treated and untreated least square mean (LSMean) A, yields, and $\mathbf{B}$, visual symptom ratings for each year. Error bars are standard errors of the LSMeans. * indicates that treatment means are significantly different (at the 5\% level) within years.

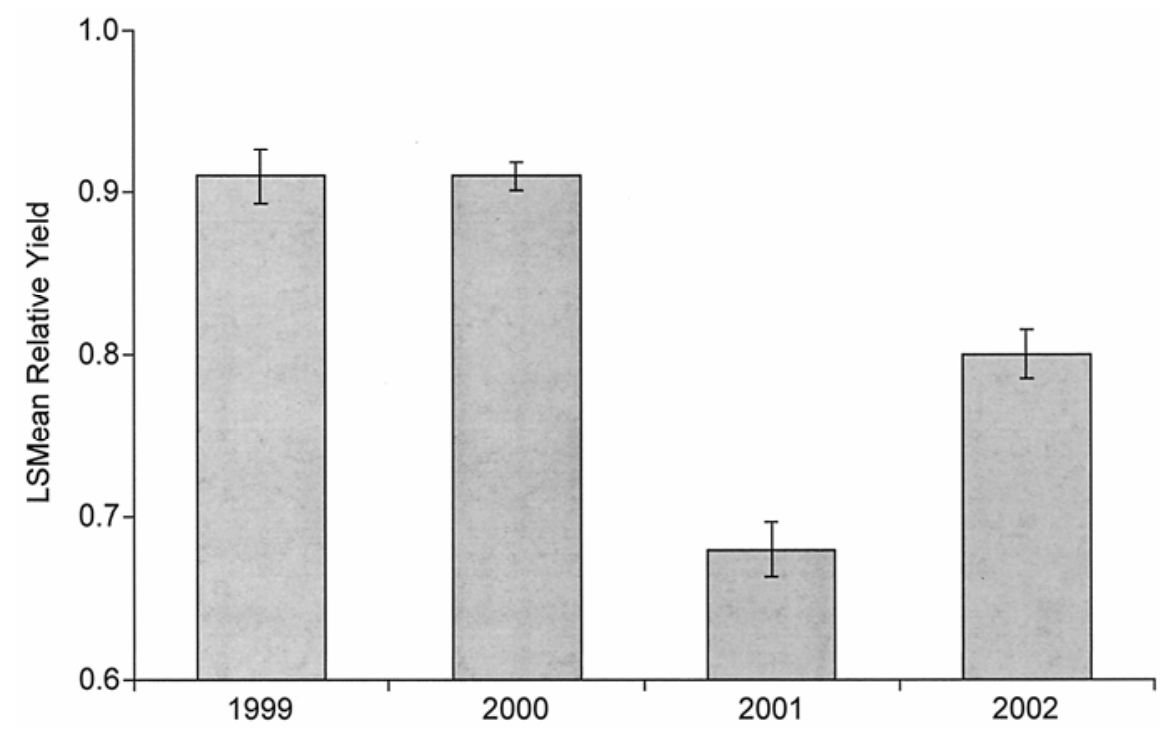

Fig. 3. Least square mean (LSMean) relative yield (a measure of Barley yellow dwarf virus [BYDV]- related yield reduction calculated as yield of an untreated plot divided by LSMean of treated plots of the same cultivar at that site-year) for each year. Error bars are standard errors of the LSMeans. effectively account for spatial variation in naturally occurring BYDV infections and subsequent yield reductions.

Because model-fit-errors were frequently spatially correlated, visual disease symptom ratings of the untreated plots, yield of GAUCHO-treated plots, yield of untreated plots, and relative yield were analyzed using the classical ANOVA, six RCBCE models, and six CE models. Table 1 shows the model with the best fit for each of these variables, which was subsequently used for the data analysis reported below. In 1999, the classical ANOVA had the best fit for all variables, indicating that blocking was effective in capturing any spatial variability in BYDV infections. In 2000, 2001, and 2002, there were only three instances where blocking was effective, and the classical ANOVA was selected as the best fit model. In all other circumstances, a CE model, which uses a spatial function to account for spatial correlation, had the best fit.

Overall yield and BYDV expression. Wheat yields across the 4 years of the experiment ranged from 4.09 to $7.94 \mathrm{Mg}$ ha $^{-1}$ (Fig. 2A). In each year, GAUCHOtreated yields were significantly higher $(\alpha$ $=0.05$ ) than untreated yields. The smallest differences between treated and untreated yields were in 1999 and 2000, when GAUCHO treatment resulted in 0.65 and $0.68 \mathrm{Mg} \mathrm{ha}^{-1}$ increases in yield, respectively. This is in comparison with 2001 and 2002, when differences between treated and untreated yield were 1.85 and $1.32 \mathrm{Mg} \mathrm{ha}^{-1}$, respectively. These data indicate that aphid pressure and/or BYDV were present in each year, and especially in 2001 and 2002.

Symptom expression in GAUCHOtreated plots was minimal, with mean values between 0 and 1 every year, indicating only a trace of BYDV symptomology (Fig. 2B). Symptom expression in the untreated plots was always significantly higher $(\alpha=$ 0.05). In 1999, 2000, and 2002, mean symptom ratings ranged from 1.6 to 2.0 , suggesting a low to moderate BYDV infestation in those years. In 2001, BYDV symptom expression was very high with a mean value of 4.4 .

Consistent with low to moderate BYDV symptom expression (Fig. 2B), 1999 and 2000 relative yield least square means were 0.91 , indicating only a $9 \%$ yield loss associated with BYDV (Fig. 3). In 2002, the mean relative yield was 0.80 . Thus, while BYDV symptom expression was only slightly higher than in 1999 and 2000, the impact of BYDV on yield reductions increased from 9 to $20 \%$. Relative yield in 2001 was 0.68 , indicating a $32 \%$ yield reduction, which was consistent with high disease symptom expression in that year.

Relationship between symptom expression and relative yield. Forty percent of the variation in relative yield was explained by visual symptom ratings $\left(R^{2}=\right.$ $0.40)$, with a high relative yield $(0.91)$ 
associated with no visual symptoms and decreasing relative yield (to 0.53 ) when visual symptoms increased to 8 (Fig. 4). However, this relationship was not consistent from year to year (Fig. 5). In 1999 and 2000, visual symptoms ranged from 0 to 4 and 0 to 5 , respectively, and the regression of these variables was not significant. In 2001, visual symptoms ranged from 1 to 8 and relative yield decreased sharply with increasing symptomology (slope $=-0.055$, $\left.R^{2}=0.50, P<0.01\right)$. In 2002, visual symptoms ranged from 0 to 6 , but there was only a weak relationship between relative yield and visual symptoms (slope = $\left.-0.026, R^{2}=0.13, P=0.04\right)$. These data (Fig. 5) indicate that the relationship between BYDV visual symptom expression and disease-related yield reductions is not consistent across environments.

The relationship between visual symptoms and relative yield was not consistent across cultivars. In fact, the cultivars were separated into three groups based on this relationship. The first group contained $\mathrm{C}$ 9663 and Roane (Fig. 6A, solid circles). These cultivars showed little to no visual disease symptoms and ratings that never exceeded 3. Additionally, these cultivars generally had high relative yields that showed little to no relationship with visual symptom expression.

In contrast, the second group consisting of FFR 555, Jackson, and Agripro Shelby (Fig. 6B, open circles) had visual symptoms as high as 7 and 8 . These cultivars showed the full range of classic visual BYDV symptoms. Even at low symptom expression, these cultivars had relative yields that were somewhat lower than those found in C 9663 and Roane, and their relative yield dropped considerably once symptom expression increased above 3. Interestingly, while all three cultivars showed the full range of visual symptom expression, their relative yields differed considerably when they expressed the most symptoms. Relative yields of FFR 555 declined once symptom expression reached 3, and continued to fall to a low of about 0.7. Relative yields of Jackson and Agripro Shelby declined once symptom expression reached 2 or 3 , but the decline was more dramatic, reaching a low of about 0.5. Consequently, while all three cultivars had similar visual ratings, FFR 555 had only about a $30 \%$ yield reduction compared with Agripro Shelby, which was about $50 \%$ reduced.

The third group, consisting of the remaining six cultivars (Agripro Hickory and Patton, C 9543, P 2580 and 2684, and USG 3209), was intermediate in visual symptom expression (Fig. 7). Similar to the second group (i.e., FFR 555, Jackson, and Agripro Shelby), relative yield tended to be high at low symptom expression, and then declined as visual ratings exceeded about 3. What distinguished this group from the other two groups was that symp- tom expression never exceeded a rating of 6. Although all of these cultivars exhibited moderate symptom expression, the relative yield associated with these symptoms was not consistent across cultivars. For example, with a high visual symptom rating of 6, C 9543 had a relative yield averaging 0.73 . In contrast, P 2684 had a high visual

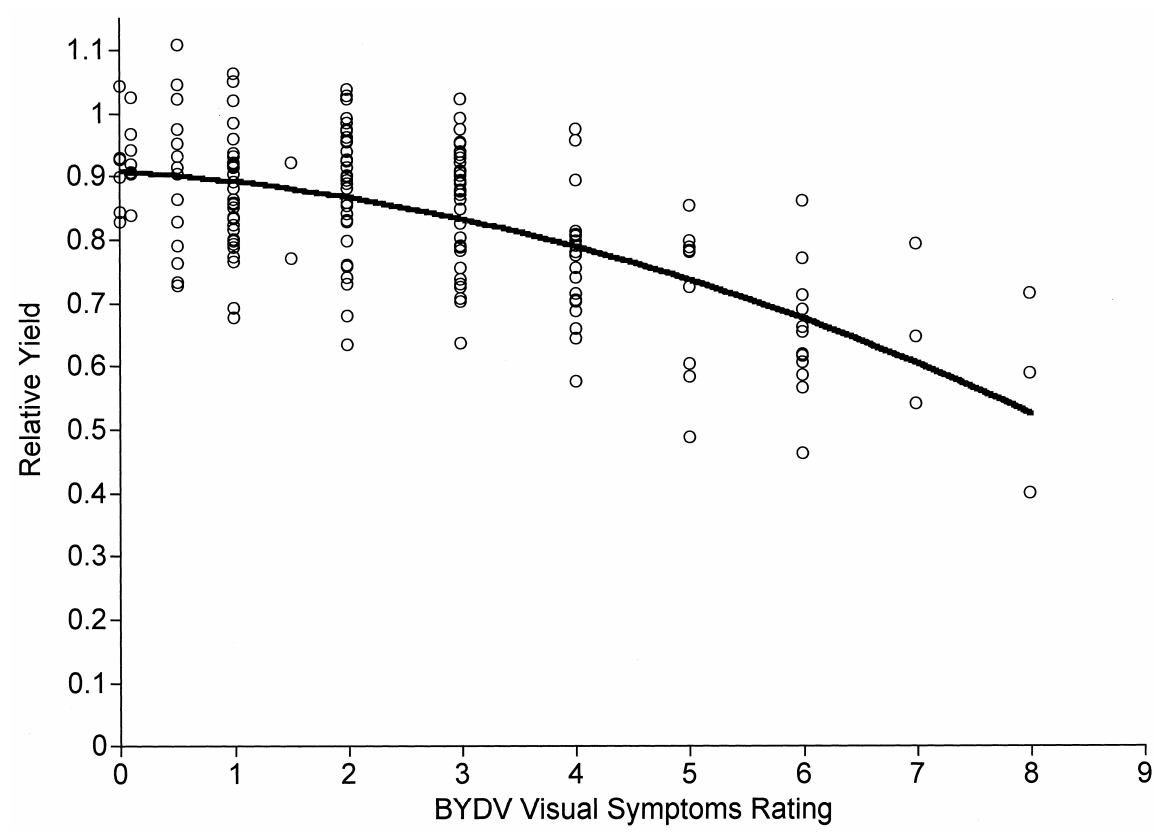

Fig. 4. Relative yield (a measure of Barley yellow dwarf virus [BYDV]-related yield reduction calculated as yield of an untreated plot divided by least square mean of treated plots of the same cultivar at that site-year) and visual symptom rating for all plots across years and cultivars.

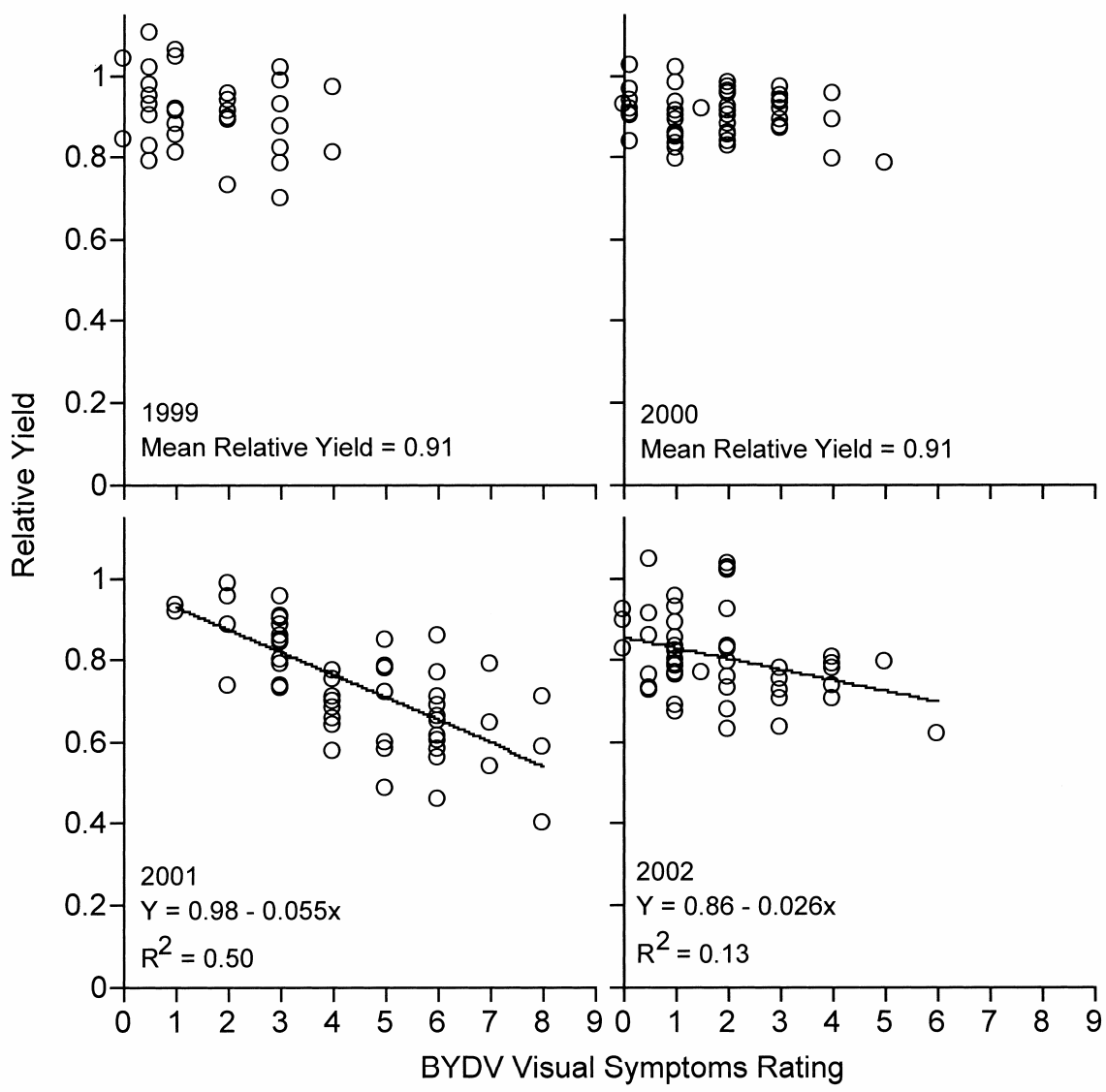

Fig. 5. Relative yield (a measure of Barley yellow dwarf virus [BYDV]-related yield reduction calculated as yield of an untreated plot divided by least square mean of treated plots of the same cultivar at that site-year) and visual symptom rating for all plots and cultivars by year. 
rating of 5 but a considerably lower relative yield of 0.49 . Consequently, at high levels of BYDV, these cultivars would look similar, with intermediate symptoms, but could have yield reductions ranging from 27 to $51 \%$.

Cultivar tolerance based on relative yield. Relative yield least square means for each cultivar and year are shown in Table 2. These values were used to rank each cultivar (within years) and to perform a consistency of performance analysis (Fig. 8). Cultivars that had consistent rank across environments had low standard deviations and consequently are located on the left half of Figure 8. Conversely, those
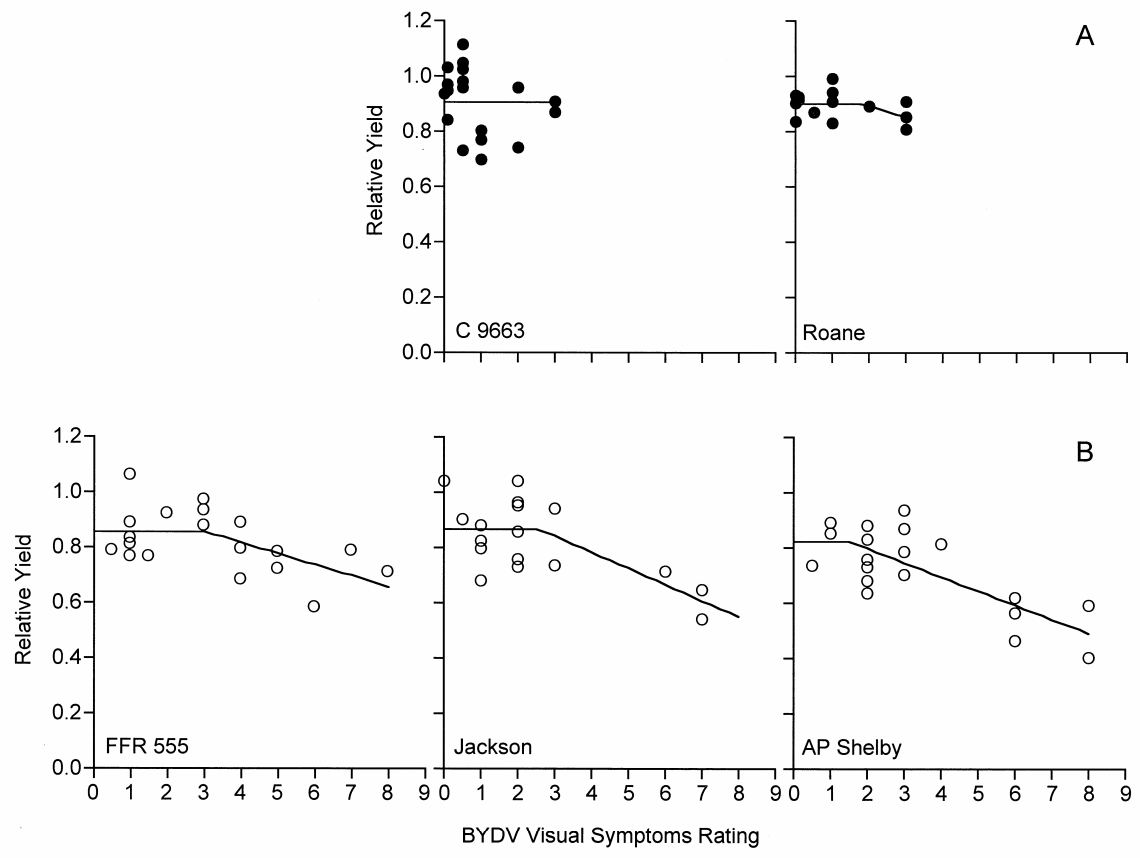

Fig. 6. Relative yield (a measure of Barley yellow dwarf virus [BYDV]-related yield reduction calculated as yield of an untreated plot divided by least square mean of treated plots of the same cultivar at that site-year) and visual symptom rating for individual cultivars: A, cultivars showing little to no visual symptoms and having high relative yields, and $\mathbf{B}$, cultivars showing the full range of visual symptoms and having reduced relative yields at high symptom ratings. Data were fit using a linearplateau function.

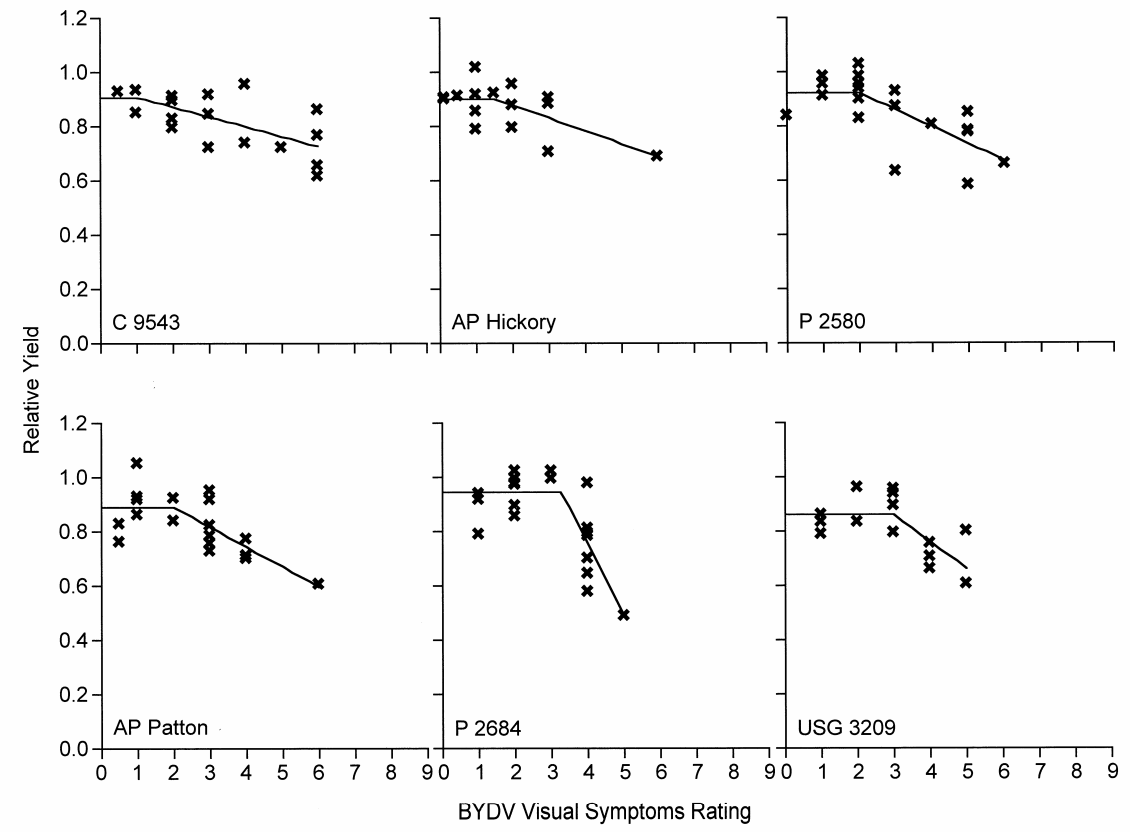

Fig. 7. Relative yield (a measure of Barley yellow dwarf virus [BYDV]-related yield reduction calculated as yield of an untreated plot divided by least square mean of treated plots of the same cultivar at that site-year) and visual symptom rating for individual cultivars showing intermediate visual symptoms. Data were fit using a linear-plateau function.

that are inconsistent performers have high standard deviations and are on the right half of the figure. Cultivars with good tolerance to BYDV perform well, have high mean ranks, and are located near the top of Figure 8, whereas those that have poor BYDV tolerance are located on the bottom of the figure. This analysis shows that the cultivars used in this experiment grouped into five clusters. Roane and $\mathrm{C}$ 9663 (Fig. 8, solid and open squares, respectively) have good BYDV tolerance, but Roane is consistently tolerant, whereas C 9663 is not. Three cultivars (Fig. 8, solid circles), USG 3209, P 2580, and Agripro Hickory, have consistent fair tolerance. Five others (Fig. 8, open circles), Agripro Patton, C 9543, Jackson, P 2684, and FFR 555 , are inconsistent and have fair-to-poor tolerance. The last cluster contains Agripro Shelby (Fig. 8, X), which consistently demonstrates poor BYDV tolerance.

\section{DISCUSSION}

Barley yellow dwarf pressure varied across the 4 years of these experiments (Figs. 2 and 3). In 1999 and 2000, visual symptoms and relative yields indicated that disease pressure was relatively light. This contrasts with 2001, when visual symptoms of untreated plots averaged close to 5 , and those of GAUCHO-treated plots were nearly 1 (Fig. 2B). Average 2001 treated and untreated yields (Fig. 2A) and mean relative yields (Fig. 3) were the lowest observed across all 4 years, indicating severe BYDV infection. The last year of the experiment, 2002, was intermediate in BYDV infection. Consequently, the data reported here include symptom expression and yield response across a large range of disease severity.

Relative yields were rarely higher than 0.9 , even when BYDV pressure was light (Figs. 3, 6, and 7). One possibility for this background $10 \%$ yield reduction could be the presence of other early-season arthropod pests such as wireworm (Coleoptera: Elateridae) or Hessian fly (Mayetiola destructor (Say)), which the GAUCHOtreated plots would have been protected from. Wireworms have not been found in North Carolina piedmont wheat fields, so damage from this pest is unlikely to have caused this yield reduction. Hessian fly biotype- $\mathrm{L}$ is an occasional wheat pest in North Carolina, but Roane is resistant to this biotype and still averaged relative yields of about 0.9 under light BYDV pressure (Fig. 6A). Consequently, Hessian fly is also unlikely to have been responsible for untreated yield reductions in the absence of BYDV. One other obvious early season arthropod wheat pest that was present in these fields was the aphid. Not all aphids colonizing wheat carry BYDV, but their feeding can still result in plant damage, tiller loss, and yield reduction. The GAUCHO-treated plots would have been protected from this feeding, and conse- 
quently would be expected to have slightly higher yields than those in the untreated plots, even in the absence of BYDV. It is possible that a combination of non-BYDVinfected aphid feeding and undetectable low levels of other arthropod pests may have contributed to untreated yield reductions.

One of the statistical considerations included in these analyses was the possibility that aphid colonization and disease infection would be clumped into hotspots within and across blocks, and consequently would result in spatially correlated ANOVA errors. This turned out to be true in 9 out of 16 data sets (Table 1). Furthermore, there appeared to be a relationship between disease severity and the failure of classical blocking to account for spatial patterns in the field. In 1999 and 2000, when disease pressure was light, the classical ANOVA was optimal for most data sets. In 2001, when disease pressure was high, blocking was ineffective in capturing spatial variability and $\mathrm{CE}$ analysis was required. In 2002, untreated, treated, and relative yields were consistent with moderate BYDV infection, and once again $\mathrm{CE}$ analysis was required to account for spatial variability of disease response across the field. Visual ratings in 2002 were similar to the lower values observed in 1999 and 2000 (Fig. 2), and consistent with those years, classical ANOVA and blocking adequately accounted for spatial patterns. These data indicate that when BYDV yield reduction or symptom expression was moderate or high, blocking and classical ANOVA were not effective. Instead, a mixed-models procedure using spatial functions to account for disease hotspots was necessary.

Differences in the relationship between visual symptom expression and relative yield loss across cultivars suggests that there might be several different tolerance mechanisms within the cultivars studied. The fact that Roane, and to a slightly lesser degree C 9663, had high relative yields of about 0.9 and visual symptom ratings that never exceeded 3 even in high BYDV environments (Fig. 6A) begs the question of whether these cultivars might not only be tolerant but actually resistant. Tolerance is defined as the ability of the host to exhibit few symptoms even in the presence of high virus titers, while resistance is the ability to reduce virus replication (2). Studies of virus titers in wheat have generally indicated that reduction in BYDV symptoms is associated with tolerance not resistance (5). However, Lorens et al. (14) found variation in virus-RNA concentrations among six wheat cultivars that differed in visual BYDV symptom expression, suggesting that resistance was present in some of these lines. Consequently, Roane and C 9663 might be good candidates for further research into BYDV resistance in wheat.
Further indications that multiple tolerance mechanisms might be present in the cultivars studied here is evident in Figures 6 and 8. For example, USG 3209 and P 2684 had similar mean ranking based on relative yield, but USG 3209 was highly consistent across environments, while $\mathrm{P}$ 2684 was one of the most inconsistent cultivars (Fig. 8). Apparently, USG 3209 has a tolerance mechanism that is more stable across environments. Also, FFR 555 and AP Shelby both displayed visual symptom ratings ranging from 1 under light BYDV pressure to 8 in high disease environments. However, FFR 555 had only a mild reduction in relative yield as symptom expression increased, while AP Shelby's relative yield decreased to approximately 0.5 under high disease pres- sure. This may also indicate that different tolerance mechanisms exist in these two cultivars.

The untreated yield, relative yield, and visual symptom data for 2002 (Figs. 2 and 3) points out an interesting dichotomy between BYDV severity conclusions based on visual symptoms and relative yield. Average 2002 visual symptom ratings (Fig. 2B) were not greatly different from those observed in 1999 and 2000, suggesting a light BYDV infection. This is also consistent with classical blocking and ANOVA being selected as the optimal statistical model for visual symptom analysis in 2002 (Table 1). However, relative yield was substantially lower in 2002 compared with 1999 or 2000 (Fig. 3), suggesting a more severe BYDV infection. Also consistent

Table 2. Separation of relative yield least square means and cultivar rankings for 1999, 2000, 2001, and $2002^{\mathrm{z}}$

\begin{tabular}{lllll}
\hline & \multicolumn{4}{c}{ Relative yield } \\
\cline { 2 - 5 } Cultivar & $\mathbf{1 9 9 9}$ & $\mathbf{2 0 0 0}$ & $\mathbf{2 0 0 1}$ & $\mathbf{2 0 0 2}$ \\
\hline Roane & & $0.96 \mathrm{ab}$ & $0.94 \mathrm{a}$ & $0.87 \mathrm{a}$ \\
C 9663 & $1.01 \mathrm{a}$ & $0.97 \mathrm{a}$ & $0.91 \mathrm{ab}$ & $0.80 \mathrm{abcd}$ \\
AP Hickory & & $0.90 \mathrm{bc}$ & $0.89 \mathrm{ab}$ & $0.84 \mathrm{abc}$ \\
C 9543 & $0.90 \mathrm{~b}$ & $0.93 \mathrm{abc}$ & $0.78 \mathrm{c}$ & $0.75 \mathrm{~d}$ \\
USG 3209 & & $0.91 \mathrm{abc}$ & $0.76 \mathrm{c}$ & $0.82 \mathrm{abcd}$ \\
P 2580 & $0.91 \mathrm{~b}$ & $0.93 \mathrm{abc}$ & $0.74 \mathrm{c}$ & $0.84 \mathrm{ab}$ \\
AP Patton & $0.91 \mathrm{~b}$ & $0.88 \mathrm{c}$ & $0.74 \mathrm{c}$ & $0.85 \mathrm{ab}$ \\
Jackson & $0.94 \mathrm{ab}$ & $0.88 \mathrm{c}$ & $0.73 \mathrm{c}$ & $0.75 \mathrm{~cd}$ \\
FFR 555 & $0.89 \mathrm{~b}$ & $0.87 \mathrm{c}$ & $0.72 \mathrm{c}$ & $0.86 \mathrm{a}$ \\
P 2684 & $0.97 \mathrm{ab}$ & $0.93 \mathrm{abc}$ & $0.71 \mathrm{c}$ & $0.80 \mathrm{abcd}$ \\
AP Shelby & $0.76 \mathrm{c}$ & $0.88 \mathrm{c}$ & $0.56 \mathrm{~d}$ & $0.75 \mathrm{bcd}$ \\
\hline
\end{tabular}

${ }^{\mathrm{z}}$ Means within a column with the same letter do not differ at the $5 \%$ level.

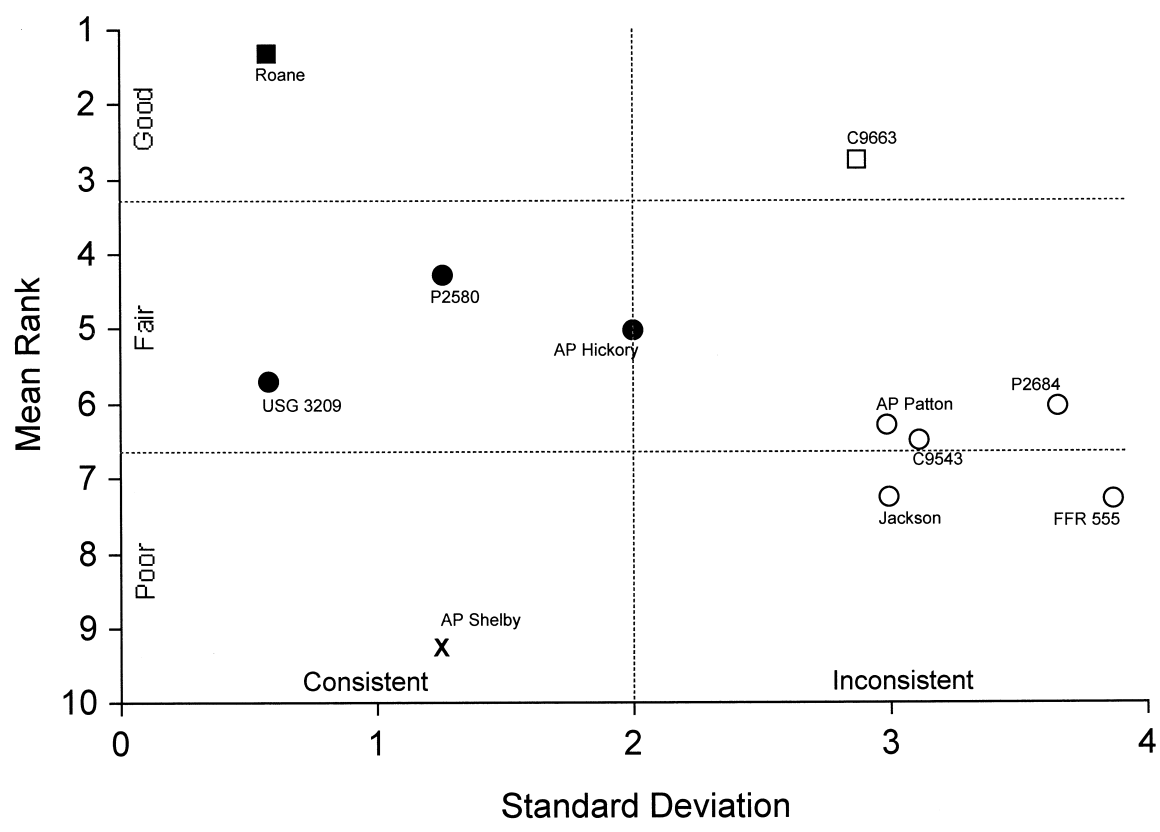

Fig. 8. Consistency of performance analysis of 11 soft red winter wheat cultivars for relative yield (a measure of Barley yellow dwarf virus [BYDV]-related yield reduction calculated as yield of an untreated plot divided by least square mean of treated plots of the same cultivar at that site-year). The mean rank of each cultivar across all site-years is on the vertical axis, which has been divided into three BYDV-tolerance categories: good is indicated by squares; fair is indicated by circles; and poor is indicated by $\mathbf{X}$. Cultivar rank standard deviations are on the horizontal axis, which has been divided into two categories: consistent, indicated by closed symbols; and inconsistent, indicated by open symbols. 
with a more severe infection in 2002 was the selection of $\mathrm{CE}$ analysis over classical ANOVA for relative yield (Table 1). Apparently, relative yield is a more sensitive measure of BYDV severity than are visual symptom ratings, and disease hotspots may cause yield reductions before visual symptoms indicate that anything more than a light infection is present.

The data presented in Figures 5, 6, and 7 indicate that the relationship between BYDV visual symptoms and yield reductions was not consistent across environments or cultivars. These data clearly demonstrate the importance of assessing BYDV tolerance over multiple environments. However, even when evaluations span multiple site-years and cultivars are segregated into groups with similar symptom expression, the degree of actual cultivar tolerance, as measured by relative yield at high disease pressure, can vary considerably (i.e., Figs. 6A and B and 7). In this study, the only case where visual disease symptom expression might have been successfully used to select tolerant cultivars was in the first group shown in Figure 6A (C 9663 and Roane). These were cultivars that showed minor (or no) symptoms, and also had little to no reduction in relative yield. Consequently, the lack of visual symptoms even under high disease pressure might be used to select highly tolerant cultivars. For all other cultivars that demonstrated a broader range of symptom expression, no single relationship could be predicted that could have been used to determine their actual yield response and consequently their tolerance to BYDV.

In conclusion, if visual disease rankings are taken under conditions similar to the highest disease pressure found in these field experiments, then cultivars with good and less-than-good tolerance might be identified. However, this approach would have selected C 9663 as having good toler- ance (Fig. 6A), even though its yield response was inconsistent across years (Fig. 8). It also would have grouped Agripro Shelby, a cultivar with consistent very high BYDV yield reductions with Jackson, which, while having fair to poor tolerance, had relative yields that were considerably higher than those of Agripro Shelby (Table 2). Although time-consuming, these results demonstrate that using relative yield is a good way to evaluate cultivar tolerance to BYDV.

\section{LITERATURE CITED}

1. Akaike, H. 1974. A new look at the statistical model identification. IEEE Trans. Automatic Control AIC-19:716-723.

2. Burnett, P. A., Comeau, A., and Qualset, C. O. 1995. Host plant tolerance or resistance for control of barley yellow dwarf. Pages 321-343 in: Barley Yellow Dwarf: 40 Years of Progress. C. J. D'Arcy and P. A. Burnett, eds. American Phytopathological Society, St. Paul, MN.

3. Carrigan, L. L., Ohm, H. W., Foster, J. E., and Patterson, F. L. 1981. Response of winter wheat cultivars to barley yellow dwarf virus infection. Crop Sci. 21:377-380.

4. Chapin, J. W., Thomas, J. S., Gray, S. M., Smith, D. M., and Halbert, S. E. 2001. Seasonal abundance of aphids (Homoptera:Aphididae) in wheat and their role as barley yellow dwarf virus vectors in the South Carolina coastal plain. J. Econ. Entomol. 94:410-421.

5. Cooper, J. I., and Jones, A. T. 1983. Responses of plants to viruses: Proposals for the use of terms. Phytopathology 73:127-128.

6. Fitzgerald, P. J., and Stoner, W. N. 1967. Barley yellow dwarf studies in wheat (Triticum aestivum L.). I. Yield and quality of hard red winter wheat infected with barley yellow dwarf virus. Crop Sci. 7:337-341.

7. Gourmet, C., Kolb, F. L., Smyth, C. A., and Pedersen, W. L. 1996. Use of Imidacloprid as a seed-treatment insecticide to control barley yellow dwarf virus (BYDV) in oat and wheat. Plant Dis. 80:136-141.

8. Gray, S. M., Chapin, J. W., Smith, D. M., Banerjee, N., and Thomas, J. S. 1998. Barley yellow dwarf luteoviruses and their predominant aphid vectors in winter wheat grown in South Carolina. Plant Dis. 82:1328-1333.

9. Herbert, D. A., Jr., Stromberg, E. L., Chappell,
G. F., and Malone, S. M. 1999. Reduction of yield components by barley yellow dwarf infection in susceptible winter wheat and winter barley in Virginia. J. Prod. Agric. 12:105-109.

10. Hoffman, T. K., and Kolb, F. L. 1998. Effects of barley yellow dwarf virus on yield and yield components of drilled winter wheat. Plant Dis. 82:620-624.

11. Isaaks, E. H., and Srivastava, R. M. 1989. An introduction to applied Geostatistics. Oxford University Press, New York.

12. Ketata, H., Yau, S. K., and Nachit, M. 1989. Relative consistency of performance across environments. Int. Symp. Physiol. Breed. Winter Cereals Stressed Mediterr. Environ., Montpellier, July 3-6.

13. Littell, R. C., Stroup, W. W., and Freund, R. J. 2002. SAS for Linear Models. SAS Institute, Cary, NC.

14. Lorens, G. F., Falk, B. W., and Qualset, C. O. 1989. Inheritance of resistance to barley yellow dwarf virus detected by northern blot analysis. Crop Sci. 29:1076-1081.

15. Neter, J., Kutner, M. H., Nachtsheim, C. J., and Isserman, W. 1996. Applied Linear Statistical Models. 4th ed. Irwin, Chicago, IL

16. Palmer, L. T., and Sill, W. H., Jr. 1966. Effect of BYDV on wheat in Kansas. Plant Dis. Rep. 50:234-238.

17. Riedell, W. E., Kieckhefer, R. W., Haley, S. D., Langham, M. A. C., and Evenson, P. D. 1999. Winter wheat responses to bird cherry-oat aphids and barley yellow dwarf virus infection. Crop Sci. 39:158-163.

18. SAS Institute 1999. SAS Release 8. SAS Institute, Cary, NC.

19. Stroup, W. W., Baenziger, P. S., and Mulitze, D. K. 1994. Removing spatial variation from wheat field trials: A comparison of methods. Crop Sci. 86:62-66.

20. Weisz, R. 2000. Small Grain Production Guide 2000-2001. R. Weisz, ed. N.C. Coop. Ext. Serv. Raleigh, NC. AG-580.

21. Weisz, R., and Tarleton, B. 1999. Imidacloprid seed treatment on farm test: Effects on barley yellow dwarf virus in soft red winter wheat. Arthropod Manag. Tests 1999.

22. Weisz, R., and Tarleton, B. 1999. Imidacloprid seed treatment: Effects on barley yellow dwarf virus, viral strains, aphid damage, yield and test weight of soft red winter wheat. Arthropod Manag. Tests 1999.

23. Zadoks, J. C., Chang, T. T., and Konzak, C. F. 1974. A decimal code for the growth stages of cereals. Weed Res. 14:415-421. 